\title{
NÍVEIS DE FLEXIBILIDADE E FORÇA MUSCULAR ABDOMINAL EM BAILARINAS SUBMETIDAS À TÉCNICA DE DANÇA MODERNA DE MARTHA GRAHAM
}

\author{
Maria Auxiliadora Monteiro \\ UEPA/UNINASSAU
}

\section{Resumo}

O objetivo do presente estudo foi analisar os níveis de flexibilidade e força muscular abdominal em bailarinas submetidas à técnica de dança moderna de Martha Graham. A pesquisa se caracterizou por um delineamento quase-experimental, onde foi utilizado como amostra 50 bailarinas, com idade média de $18 \pm 5,29$ anos, de um grupo de dança do Colégio Gentil Bittencourt, localizado no Bairro Nazaré, em Belém, Pará. A amostra foi submetida ao programa de dança moderna de Martha Graham durante 12 semanas. Para a avaliação das variáveis foram utilizados: a goniometria (na avaliação da flexibilidade) nos movimentos espacate anteroanterior/flexão, espacate antero-anterior/ extensão, espacate latero-lateral, extensão, elevação frontal e elevação lateral da articulação do quadril, o máxima de 1 minuto (na avaliação da força muscular abdominal). Foi realizada a análise estatística descritiva com o objetivo de estimar as medidas de tendência central (média e mediana) e variação (desvio-padrão e erropadrão) além da distribuição de frequências, absolutas e relativas. E a análise estatística inferencial por meio do teste de Shapiro Wilk para a análise da normalidade da amostra; o teste de

\section{Abstract}

Levels of flexibility and abdominal muscle strength in dancers submitted to Martha Graham's modern dance technique The aim of the present study was to analyze the levels of flexibility and abdominal muscle strength in dancers submitted to Martha Graham's modern dance technique. The research was characterized by a quasi-experimental design, where 50 dancers, with an average age of $18 \pm 5.29$ years old, from a dance group at Colégio Gentil Bittencourt, located in Bairro Nazaré, in Belém, Pará, were used as a sample. The sample was submitted to Martha
Wilcoxon (não-paramétrico) e o teste t de Student (paramétrico) para comparação entre as médias dos dois diferentes momentos de testagem (antes e depois do treinamento). Nos resultados pôdese observar aumentos significativos, no pósteste, nas variáveis: flexibilidade (para todos os movimentos - espacate antero-anterior/flexão $(\Delta=4,43$ graus; $p=0,039)$, espacate anteroanterior/extensão $(\Delta=5,02$ graus; $p=0,004)$, espacate latero-lateral $(\Delta=12,91$ graus; $p=0,014)$, extensão $(\Delta=8,40$ graus; $p=0,000)$, elevação frontal $(\Delta=15,57$ graus; $p=0,000)$ e elevação lateral $(\Delta=10,11$ graus; $p=0,000)$, e nos níveis de força abdominal ( $(\Delta=2,70$ repetições; $p=0,000)$. Desta forma, pôde-se concluir que a intervenção da dança moderna pode gerar aumentos na amplitude de movimento articular, nos níveis de flexibilidade e na força muscular abdominal em sujeitos jovens.

\section{Palavras-chave:}

Dança Moderna; Atividades físicas; Força Muscular; Amplitude muscular.

Graham's modern dance program for 12 weeks. For the evaluation of the variables, the following were used: goniometry (in the assessment of flexibility) in the anteroposterior / flexion movements, anteroanterior splits / extension, latero- lateral extension, frontal elevation and lateral elevation of the hip joint, the maximum of 1 minute (in the evaluation of abdominal muscle strength). Descriptive statistical analysis was performed in order to estimate measures of central tendency (mean and median) and variation (standard deviation and standard error) in addition to 
the distribution of frequencies, absolute and relative. And inferential statistical analysis using the Shapiro Wilk test to analyze the sample's normality; the Wilcoxon test (non-parametric) and the Student test (parametric) for comparison between the means of the two different testing moments (before and after training). In the results, it was possible to observe significant increases, in the post-test, in the variables: flexibility (for all movements - antero-anterior splitting / flexion ( $\Delta=4.43$ degrees; $p=0.039$ ), antero-anterior splitting $/$ extension $(\Delta=5.02$ degrees; $p=0.004$ ), laterolateral splits $(\Delta=12.91$ degrees; $p=0.014)$, extension $(\Delta=8.40$ degrees; $p$

\section{INTRODUÇÃO}

Martha Graham nasceu em 11 maio de 1894, na Pensilvânia. Descendia de irlandeses, seu pai era médico psiquiatra e católico e, sua mãe presbiteriana e uma mulher muito dedicada. Martha foi confirmada presbiteriana, frequentou essa igreja e foi nela que dançou pela primeira vez, ainda criança. Em 1911, aos 17 anos, assistiu pela primeira vez a um espetáculo de dança: ao ver Ruth St. Denis dançar percebeu que seria bailarina.

Roger Garaudy (1994) diz que um dos sentimentos mais perturbadores que experimentamos quando estamos diante de Martha Graham é imaginarmos que pelo corpo frágil desta mulher foram expressos os tormentos, as paixões e as esperanças mais ardentes do nosso século. Cláudia Martinelli Gama (1993), a tradutora de sua autobiografia, aponta: ela "explorou ardorosamente as paixões em que se alicerça a alma humana".

De acordo com Martha Graham, a formação de um bailarino leva cerca de 10 anos e inclui o estudo e o exercício da técnica, bem como o cultivo do ser, do qual emerge algo, mas não do nada e sim de uma grande curiosidade. Para ela, a ambição não é o suficiente, a necessidade é tudo. É a partir dessa necessidade que as lendas de viagens da alma são recontadas com toda sua tragédia, amargor e doçura de viver. E é nessa necessidade que "o ímpeto da vida alcança a mera individualidade do intérprete e, enquanto o individual se torna maior, o pessoal se torna menos pessoal. E existe a graça". Com relação a essa necessidade, Jung nos esclarece: "o inconsciente é futuro na forma
= 0.000), frontal elevation $(\Delta=15,57$ degrees; $p=$ 0.000 ) and lateral elevation $(\Delta=10.11$ degrees; $p$ $=0.000$ ), and in the abdominal strength levels ( $\Delta=$ 2.70 repetitions; $p=0.000$ ). that the intervention of modern dance can generate increases in the range of articular movement, levels of flexibility and abdominal muscle strength in young subjects.

\section{Keywords:}

Keywords: Modern Dance; Physical activities; Muscle strength; Muscle amplitude.

ou disfarce no passado. É menos desejo do que dever" (JUNG, 2002, p. 12).

Diante disto, a dança não passa por uma definição conceitual, nem pela descrição e reunião de seus elementos constituintes, mas antes pelo significado que ela é capaz de acessar. A dança é uma atividade humana e como tal deve ser entendida em termos de significados, objetivos, razões e finalidades e não somente a partir de eventos ou causas.

A dança é a arte do movimento, onde, através do controle muscular e de movimentos coordenados, atinge-se a plasticidade necessária para possibilitar a realização de movimentos técnicos. O corpo humano é o instrumento de arte da dança, sendo preciso discipliná-lo e desenvolvêlo, a fim de que atinja toda a plasticidade, pureza de linhas e expressão possíveis. Para tal, é exigido aos bailarinos um alto grau de amplitude de movimentos para a performance (ACHAR, 1998).

A flexibilidade é a qualidade física de maior importância para a dança. A adoção da prática de trabalhos de preparação física diária, absorvida aos hábitos dos bailarinos, proporcionará bem-estar permanente, fato que pode ser observado logo após o início dos programas. Os exercícios utilizados para desenvolver a flexibilidade são os exercícios de alongamento, utilizando toda a amplitude do movimento, atuando sobre a elasticidade muscular, propiciando a manutenção dos níveis de flexibilidade ou utilizando exercícios que forçam a obtenção dos limites além do normal, atuando sobre a elasticidade muscular e a mobilidade articular, proporcionando um aumento dos níveis de flexibilidade (LEAL, 1998). 


\section{DEFININDO A DANÇA MODERNA DE MARTHA GRAHAM}

A dança moderna surge estabelecendo uma ruptura com os valores já existentes na arte do balé clássico o qual buscava o equilíbrio, o voo e a leveza na harmonia dos movimentos. 0 desafio de conquistar a gravidade é um dos pontos mais relevantes, mas não necessariamente o principal. A dança moderna nasce com uma relação mais próxima do solo, que era considerada um elemento maternal, pela essência fértil, por isso a necessidade de alcançar um contato vital com ela.

A arte da dança moderna se desenvolveu a partir da inspiração e criatividade individual do artista. Como exemplo desse desenvolvimento criativo, temos 0 uso do centro do corpo, sendo o tronco propiciador dos movimentos para as outras partes do corpo e a utilização do chão, não apenas para o suporte dos pés descalços, mas sim como mais uma opção para os bailarinos deitarem, sentarem, rolarem e desafiarem o equilíbrio (HOROSKO, 1991).

No final do século XIX, surgiram Isadora Duncan, Loie Fuller e Ruth Saint Denis, pioneiras da Dança Moderna, as quais influenciaram várias gerações, como a de Martha Graham, Doris Humphrey, José Limon, Merce Cuningham, Alvin Nikolais e Lester Horton (CAMINADA, 1999).

Com 14 anos, em 1908, Graham se mudou para Santa Bárbara, Califórnia, onde terminou o ensino secundário e durante três anos frequentou uma escola de arte dramática e, em 1916, com 22 anos entrou na primeira escola de dança dos EUA, a Denishawn school. Em pouco tempo passou de estudante a uma professora assistente. Chegou a ser bailarina principal e trabalhou com Ted Shawm como super estrela de um balé chamado Xochtil.

Martha Graham permaneceu na Denishawm por aproximadamente oito anos, saindo em 1923 para Viles Follies de Greenwinch, era uma espécie de casa de shows da Broadway. A partir deste momento ela teve um grande reconhecimento, permanecendo por três anos. Em 1925 deixou a Viles Folles de Greenwinch, já pensando em carreira independente, mas neste mesmo período conseguinte trabalhou na escola Eastman de música em Rochester, em Nova Iorque e também na escola John Murray Anderson em Nova lorque.
Em Nova lorque, 18 de abril de 1926, estreou com sua companhia, caracterizada como os estudantes da Eastman, as coreografias projetavam uma grande influência do repertório da Denishawn, com características exóticas, o balé era chamado de Flauta Krisma, uma espécie de ensaio, como se fosse experimentação de padrões de movimentos que o corpo pode explorar cada vez mais. A partir deste momento notava-se o surgimento de uma movimentação diferente e sofisticada.

Englobando todo esse contexto, o conhecimento da dança recai na necessidade de descrever sua história, destacando a identidade de um povo por meio de um manifesto da cultura. Segundo Aquino (2007, p. 97) "o pensamento não é operação de um órgão do corpo e sim da alma: por algumas de suas faculdades ela move o corpo e o faz crescer, por outras, ela pensa".

Nessa trilha, Martha Graham procurou criar e codificar uma técnica de dança moderna que foi aceita por uma notável geração de coreógrafos e bailarinos no mundo desta arte. Qualquer pesquisa baseada em Martha Graham não é fácil, haja vista que esta artista se manifestou por meio de coreografias deixando pouca literatura sobre a sua filosofia.

A dança de Graham firmou sua legitimidade a partir de 1930, por meio da audácia e extravagância de suas criações. A artista foi considerada a mais antiga estrela e o expoente máximo desta arte por muitos estudiosos, como Baril (1977), Au (1988), Dobbels (1990) e Gardner (1996). Ela mudou valores já existentes na arte da dança e inventou uma nova forma de dançar, permanecendo assim na história.

Por mais que esta técnica sobreviva no tempo, há a necessidade de que, no contexto da dança moderna atual, seja conhecida na essência estética, histórica e filosófica, pois ela, segundo Baril (1977), Garaudy (1981) e Gardner (1996), é sinônimo de dança moderna. Assim como aula de balé é imprescindível para o bailarino clássico, a aula de Graham é necessária para o bailarino moderno.

Isto tudo nos leva a acreditar que não seja só pela importância técnica, como também pela gama literária que se torna importante para a formação do bailarino com trabalho para a continuação e divulgação e marco da dança hoje, com avanços 
em novas pesquisas, para que o registro da história da dança fique presente, hoje e sempre.

Graham destacou-se em vários depoimentos que recebeu em seus primeiros ensinamentos relacionados para a dança de seu pai que dizia que o movimento nunca mente. Sendo o pai de Martha Graham um médico alquimista, hoje chamado psiquiatra, percebia as reações e os gestos de cada paciente, por isto conhecia o momento da expressão e movimentação de cada um.

Graham defendia que a prática se adquire pela repetição isto significa que, deve-se aprender a dançar por meio da prática da dança, visto que, aprende-se a viver, vivendo, os princípios são os mesmos.

Para ela, cada um é a execução de um dedicado e preciso conjunto de atos, físicos ou intelectuais, das quais surge uma forma de realização, uma percepção de o próprio ser, uma satisfação do espírito. Em algumas áreas a pessoa se torna um atleta de Deus (GAMA apud GRAHAM, 1993).

A proposta de Graham está baseada num pensamento filosófico que se reflete na bagagem corporal, pois, no momento de ocorrer a praxe na dança, tudo vem a ser relevante, não só nos aspectos da filosofia como nos corporais e cênicos.

A dança de Martha Graham ultrapassa séculos, suas obras tinham como cunho de destaque o religioso, a psicanálise e pelas profundidades das reflexões, o pensamento filosófico, além de projetar os problemas político-sociais, que refletiam em sua dança dramaturga. Acreditase que sua dança é difundida mundialmente por este contexto histórico na literatura e expansão técnica, constitui o alicerce sobre a dança hoje.

A dança de Graham foi percebida e respeitada pelo público, o que pode ser notado pela aceitação da classe artística, tornando-se presente na história, na qual teve o privilégio de sentir e vivenciar o destaque de suas criações por quase 70 anos (1926-1991), sem contar a influência que exerce nos dias atuais, totalizando quase 118 anos que seu trabalho marca o universo da dança moderna.

Martha Graham (GAMA apud GRAHAM, 1993, p. 14) em "Memórias de sangue" afirma que "O corpo é um traje sagrado. É o primeiro e último traje da pessoa: é nele que se entra na vida e com ele se parte dela; deve ser tratado com honra, e com alegria e medo também". Esta reflexão destaca as ideias de cunho filosóficos de Graham, ao contexto da verdade e razão, em que ela medita sobre o corpo, o qual é a profunda consciência para a sua arte.

Martha Graham, ao codificar a arquitetura dos diversos movimentos, dá ênfase a um novo idioma para a dança, valorizando o corpo como único, observando a ação da percepção e da corporeidade refletidas pelos sentimentos e expressões ressaltadas na realidade dos contrastes e conflitos sociais.

A dança é uma atividade que proporciona infinitas possibilidades de trabalhar a sensibilidade corporal e o espírito. Segundo Moreira (2004):

A motricidade humana permite a realização de um estudo com cientificidade, visto o desenvolvimento do seu campo teórico. A área de estudo da motricidade humana investiga os motivos que levam o homem a fazer um gesto, a escolhê-lo entre todos os possíveis, a executá-lo da forma como o faz, a estudar o modo como o corrige, a estudar os porquês da relação de cada corpo com os outros corpos e com todas as restantes formas de vida (MOREIRA, 2014, p. 19).

Sendo assim, entendemos a sensibilidade na arte da Dança Moderna, como uma possibilidade de conhecimento do movimento na técnica de Martha Graham, uma forma de apreensão da realidade, pela a experiência vivida e partilhada com o outro, enquanto mundo, é uma das vias para compreendermos não só a movimentação em si, mas o processo de transmissão de uma dança, com um corpo que fala transfigurandose em performance coreográfica, por meio do "fenômeno da emoção "com um partilhar motriz.

\section{A TÉCNICA DA DANÇA MODERNA DE MARTHA GRAHAM}

As inovações promovidas por Martha Graham no mundo da dança mudaram a conceituação da dança tradicional, baseada no equilíbrio, na plasticidade e na leveza, para uma dança fundamentada no desafio do equilíbrio, na intimidade com o chão (a mãe terra), nos problemas sociais e na dramaticidade de uma dança chamada moderna.

A técnica de Martha Graham permitiu avanços e trouxe novos valores, influenciaram coreógrafos, professores, escolas e bailarinos no mundo 

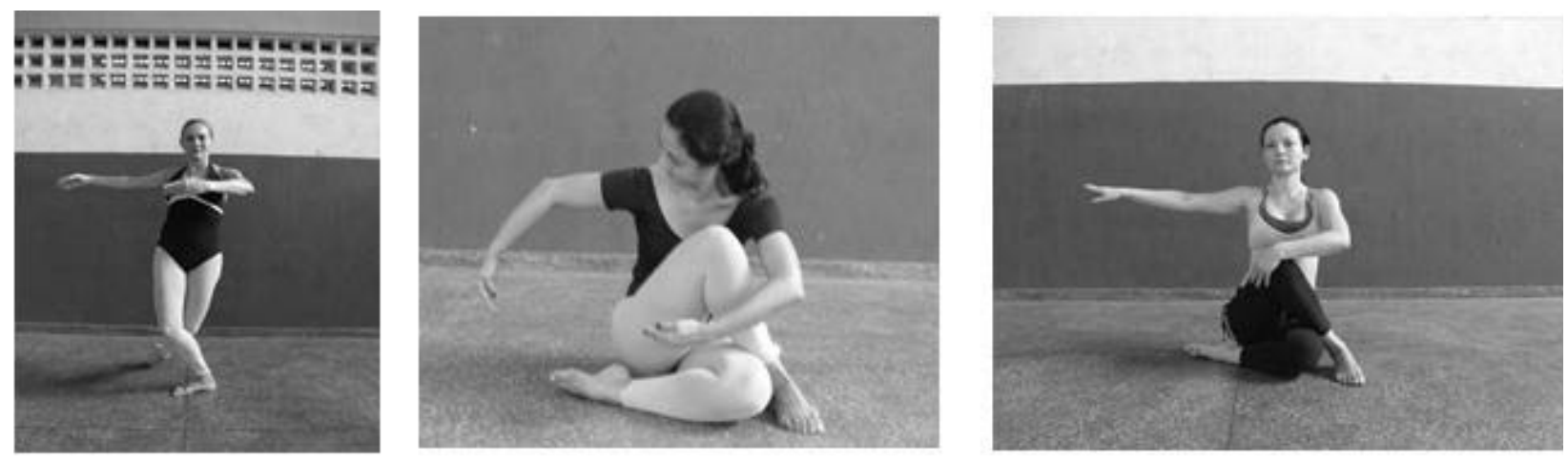

Figura 1 - Desenvolvimento da posição em pé para a posição sentada.

Fonte: A. Monteiro Dance Company. Bailarinas: Adalnice Duarte, Cristiani da Rocha e Simone Veiga. Poses na Técnica de Martha Graham

todo, criando um amplo leque para o surgimento de escolas de dança, companhias, grupos independentes que trouxeram uma nova estética para a dança hoje.

A dança antes de Martha Graham precisava de codificação, como já existia no balé clássico. Até então não havia nenhum registro da técnica da dança moderna, embora já houvesse iniciado na dança a tendência que se diferenciava da estrutura clássica. Dançava-se livremente, sem haver pesquisas baseadas nas leis naturais dos movimentos, sentia-se necessidade de dados reais para organizar o que estava surgindo desta arte.

Quem dançava fora dos modelos clássicos do balé, não tinha credibilidade e enfrentava grandes problemas e sofria constantes críticas de público. A dança de Isadora Duncan (1878-1927), uma das pioneiras na dança moderna, foi acusada fazer a dança, fora dos padrões sociais e morais da época, além de ser considerada monótona, sem avanços técnicos, limitando-se ao que queria expressar para o público, visto que a legitimidade da dança era restrita apenas ao balé clássico. Segundo os espectadores a apreciação dos aspectos relacionados à linguagem expressiva, à criatividade e à estética deixava a desejar. Mesmo assim, os novos coreógrafos e bailarinos prosseguiram corajosamente.

Hoje, percebe-se a necessidade do diálogo da dança moderna com outras áreas do conhecimento. Os profissionais precisam perceber que não se pode caminhar apenas numa dimensão, deve-se buscar novas vertentes para que a dança possa contemplar as mais diversas perspectivas em termos de conhecimento, valor formativo social e estético.
Antes do surgimento da técnica de Martha Graham, a dança se legitimava apenas através dos movimentos academicistas do balé clássico, que foram também desafiados pela rebeldia da dança natural de Isadora Duncan e outros que vieram romper o contexto que existia até o momento na caminhada desta arte.

Portanto a "Filosofia de Martha Graham" fundiu o academicismo do balé clássico com o espontaneísmo da dança livre de Isadora Duncan e elaborou nova técnica e método.

Martha Graham caracterizou a sua técnica de dança moderna nos movimentos intencionais, vindo da emoção, somando a fluência do movimento que vem aparecer na projeção da expressão.

Na técnica da dança moderna o corpo se dilata e se contrai se estica e se encolhe, deste modo se produz a relação encadeada e contínua entre o corpo interior e o espaço exterior. A técnica de Martha Graham, notadamente, promove toda movimentação do corpo, como: torsão, alongamento, contração, entre outros, e estão inseridos neste pensamento.

Flexionar-se, contorce-se e curvar-se são movimentos diferenciados que fazem parte dos movimentos característicos desta técnica. O ponto primordial do seu trabalho parte da pélvis, de onde vem o "Ende hor" (rotação externaarticulação coxofemoral). A intenção deste movimento vem de dentro para fora, com gestos naturais e flexíveis. Deste centro vem toda a energia e precisão de toda movimentação que se completa, atingindo todos os seguimentos do corpo em um todo (figura 1 ). 


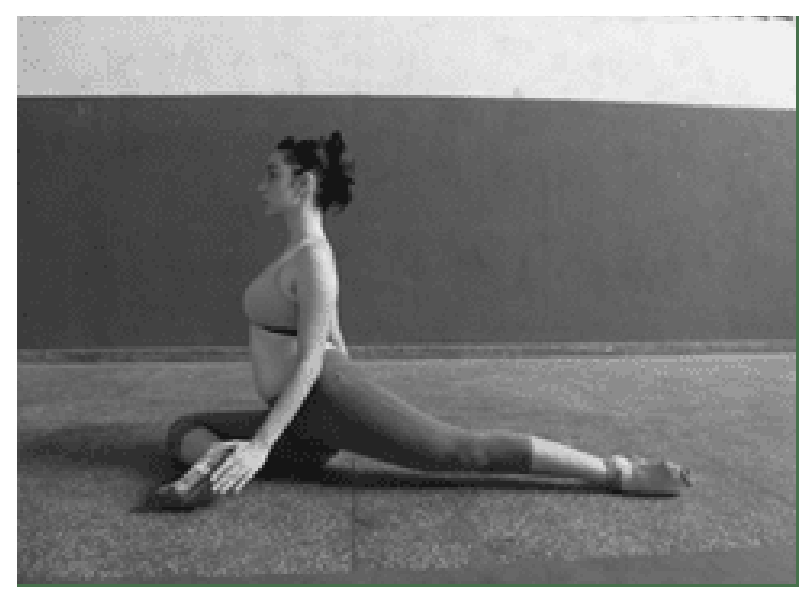

Figura 2 - Sentado com extensão da perna para trás. Fonte: A. Monteiro Dance Company. Bailarinas: Carina e Marina Fleury. Poses na Técnica de Martha Graham.

O corpo da artista se transforma em ondas luminosas, onde a dança tem como vocação de ritmar as sensações internas em uma música virtual, música dos olhos, vindo a sensação do corpo dançante como o corpo vibrátil, confluência de dinâmicas sutis.

A amplitude e a velocidade dos movimentos dos bailarinos são efeitos da potência da dinâmica do fôlego que se revela ao grau de intensidade e tensão do movimento. O alternar-se da inspiração e da expiração fornece aos bailarinos a motriz dos princípios de tensão/relaxamento, com a promessa de múltiplas interpretações.

Além de todas estas peculiaridades dos movimentos desta técnica, observa-se uma das expressões dinâmicas do movimento mais eficazes do movimento sucessivo, a espiral. São verificados também os rodopiantes, nos solos (figuras 2 e 3 ).

A técnica elaborada pela bailarina repousa sobre um jogo permanente entre a perda e recuperação do equilíbrio. O consentimento na queda, o abandono do corpo às leis da gravidade é ali assumido como a condição do salto e do voo. A dança é toda percorrida por saltos e quedas acrobáticos, e essa circulação encarna, aos olhos da coreógrafa, o próprio movimento da vida (figuras 4 e 5 ).

Nesta técnica, Graham criou uma movimentação na base sentada, onde houve uma preocupação com o ato de respirar, fazendo uma diferenciação

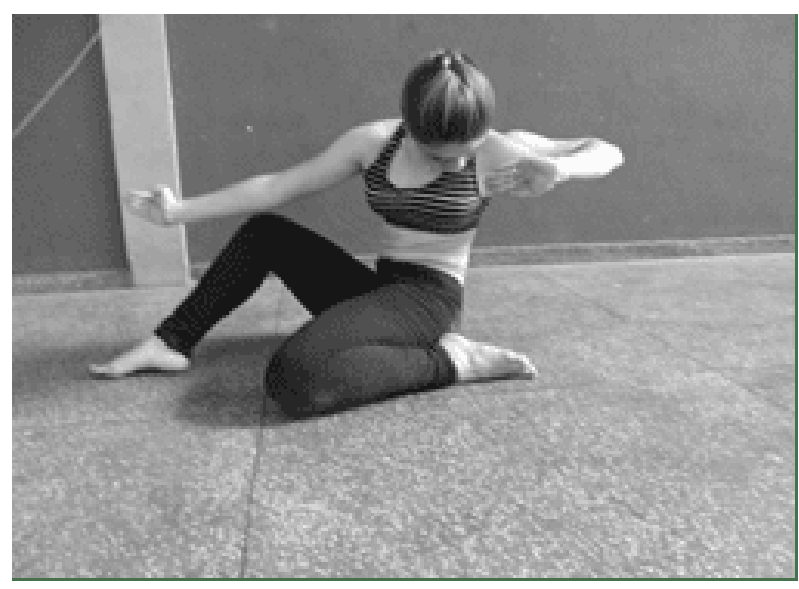

Figura 3 - Voltas do tronco na base fixa.

Fonte: A. Monteiro Dance Company. Bailarinas: Carina e Marina Fleury. Poses na Técnica de Martha Graham.

das outras técnicas. Um dos mais destacados movimentos é a "contracion" e o "release", trabalho localizado no tronco, onde ocorre, esta fundamentação da respiração por todo o processo de aula da técnica de Martha Graham.

\section{DISCUSSÃO DA FLEXIBILIDADE, E DA FORÇA MUSCULAR}

Os resultados apresentados no presente estudo revelaram aumento significativo da amplitude do arco articular de todos os movimentos analisados, dos níveis de flexibilidade e da força abdominal do momento pré para o pós-teste.

O estudo de Alricsson et al. (2003) corrobora os resultados encontrados na presente pesquisa para a variável flexibilidade, pois investigou os efeitos do treinamento de dança em períodos de três e oito meses em sujeitos jovens de ambos os sexos. A avaliação da amplitude de movimento foi realizada através de goniometria e revelou que os movimentos de flexão-extensão de coluna, flexão de quadril e flexão de tornozelo apresentaram aumentos significativos em comparação ao grupo controle. Mostrou também aumentos da amplitude de movimento quando comparados os momentos de avaliação nos períodos de três e oito meses, flexão-extensão da coluna torácica com 7.5 graus de aumento depois de três meses $(P=$ 0.05 ) e com nove graus depois de oito meses ( $P$ $=0.03$ ). Observou-se que em ambos os estudos o período de intervenção da dança foi suficiente para apresentar um efeito positivo na amplitude de movimento articular dos sujeitos. 


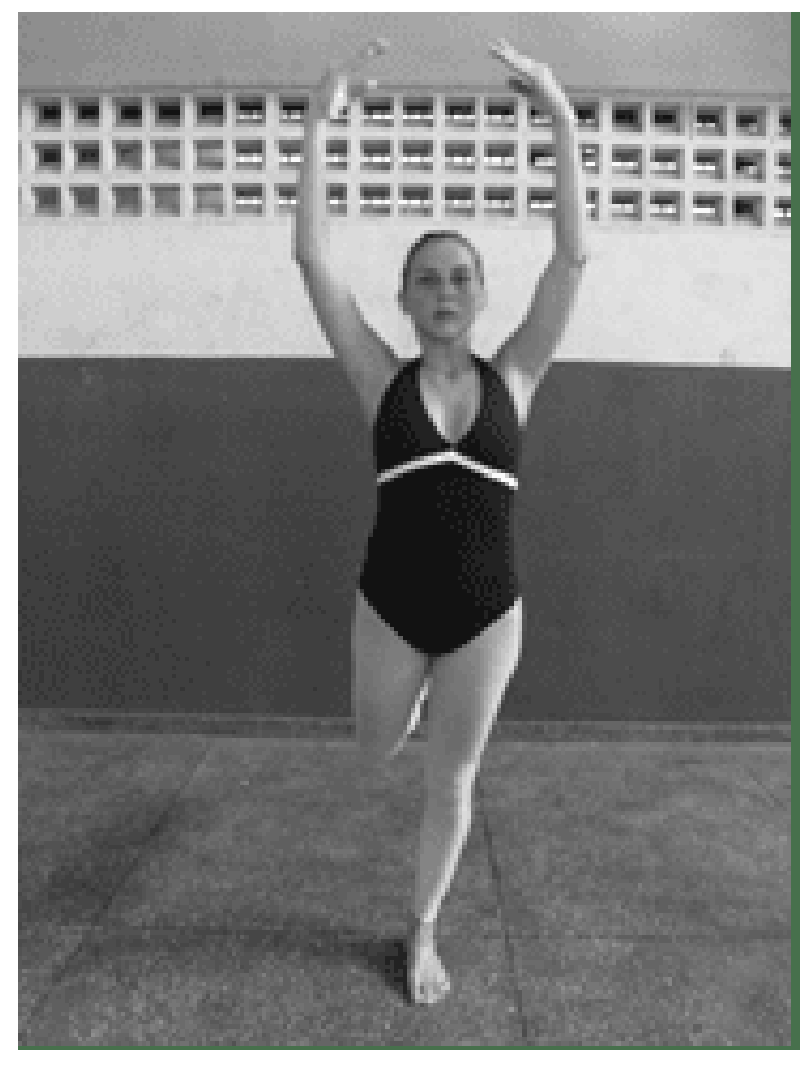

Figura 4 - Plié com Perna elevada para trás.

Fonte: A. Monteiro Dance Company. Bailarinas:

Adalnice Duarte e Simone Veiga. Poses na Técnica de Martha Graham.

Steinberg et al. (2006) observaram a relação entre a idade e a amplitude de movimento articular do quadril de 1320 dançarinas, participantes de ballet clássico, dança moderna e jazz, e 226 não dançarinas na faixa etária de oito a 16 anos. Verificaram que os movimentos de flexão plantar do tornozelo e rotação lateral do quadril não apresentaram diferenças entre os praticantes dos diversos tipos de dança investigados. No entanto, as amplitudes desses movimentos diminuíram em relação à idade entre os sujeitos não praticantes de dança. Para a flexão de coluna lombar e da musculatura posterior de coxa, as amplitudes aumentaram de acordo com a idade entre os dançarinos. Isso sugere que a continuidade da prática de dança pode aumentar a amplitude de movimento articular, sustentando os achados encontrados na presente pesquisa.

Nesse sentido, parece que independentemente do tipo de dança praticado os níveis de amplitude de movimento se apresentam semelhantes ou com pequenas diferenças de amplitude em alguns movimentos específicos e característicos do

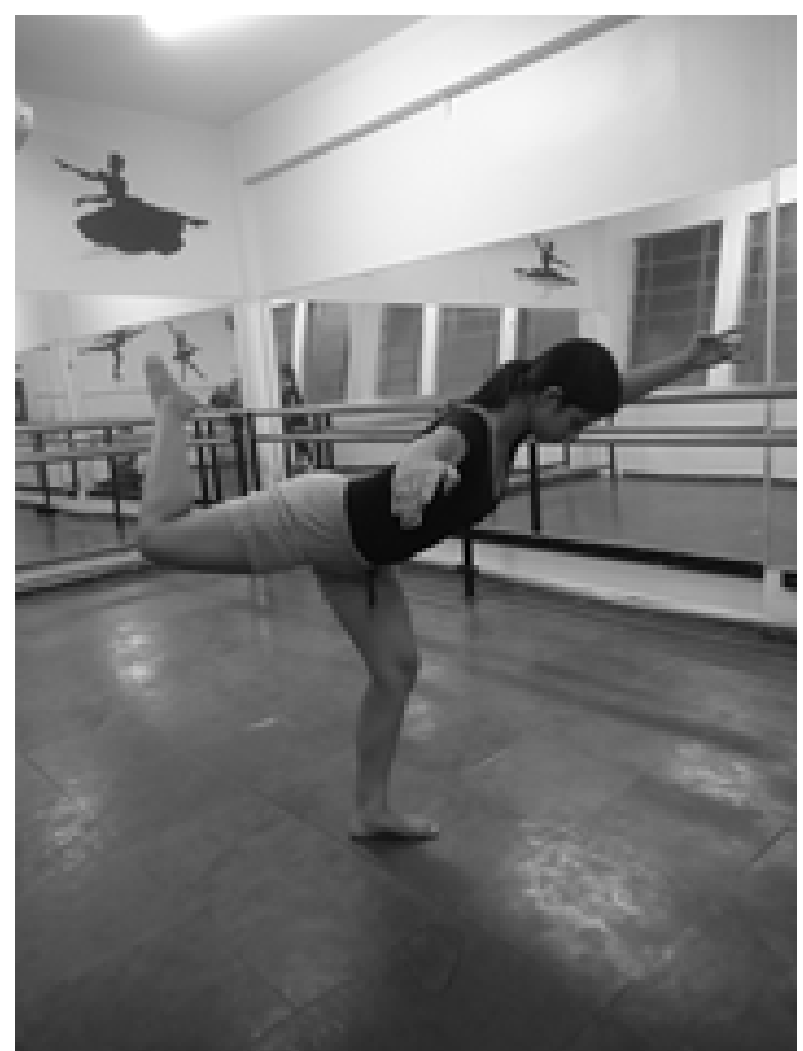

Figura 5 - Voltas do tronco na base fixa.

Fonte: A. Monteiro Dance Company. Bailarinas:

Adalnice Duarte e Simone Veiga. Poses na Técnica de Martha Graham.

estilo praticado. Dessa forma, Silva et al. (2008) apontaram que em relação aos indicadores dos níveis de flexibilidade, praticantes de ballet clássico apresentaram valores semelhantes nos movimentos de flexão de quadril e rotação lateral do quadril e maiores no movimento de abdução de quadril que os praticantes de dança contemporânea.

Da mesma forma, Okuneye, Adeogun e Idowu (2010) investigaram os efeitos de um programa de dança aeróbica de baixo impacto sobre a flexibilidade do tronco e da força abdominal em adultos jovens do sexo masculino. Encontraram aumentos significativos em ambas as variáveis analisadas após um período de seis semanas de intervenção. Hui et al. (2009) também observaram melhoras na força muscular, na flexibilidade e no bem-estar psicológico de pessoas participantes de intervenções de dança em idades mais avançadas. Conforme os resultados encontrados no presente estudo, pode-se concluir que a intervenção da dança moderna pode gerar aumentos na amplitude de movimento articular (flexibilidade) e na força muscular abdominal em sujeitos jovens. 


\section{CONSIDERAÇÕES FINAIS}

Observou-se que no momento da exteriorização do movimento é necessário esforço físico para a realização da dança. A dança moderna cria possibilidades de dramaticidade que requerem condicionamento físico para a expressão de seus movimentos técnicos e artísticos. Assim, desenvolve a força, a resistência e a flexibilidade que dão suporte para a estruturação de novas posturas sobre as quais se estrutura uma nova ordem gestual da dança.

Destacamos, a importância da técnica de Martha Graham e sua contribuição para a história da dança, sob os aspectos filosóficos e a partir do olhar de uma aula de flexibilidade, e força muscular abdominal, visto que a técnica de Graham trabalha a expressão, a corporeidade, ou seja os sentimentos, a postura e as qualidades físicas. Isto tudo motiva diversas formas de exploração de movimentos tanto no campo estético como expressivo, ajudando no desenvolvimento global de quem as vivências.

Pretendemos com esta pesquisa, contribuir com os profissionais da área de dança moderna ressaltando o papel valorativo da metodologia de uma filosofia em Martha Graham, sob o enfoque da flexibilidade, visto que esta técnica, que se desenvolveu e marcou a história da dança, influenciou todo o século XX e ainda influencia o século atual.

A cultura da dança é uma realidade que "não precisa de significado", justamente porque ela própria constrói a significação, por meio do corpo, que expressa valores em todas as dimensões. A cultura e o homem estão indissoluvelmente incorporados. Só existe cultura por meio do homem, e o homem só consolida sua existência pela cultura, que é um ato da imaginação humana.

Martha Graham foi responsável por repassar a cultura da dança moderna que permanece inserida no contexto da dança atual e recai na história de gerações e gerações. Esta corrente filosófica de uma técnica foi criada para seu corpo, mas em curto tempo fez e faz parte do cotidiano e da história da dança.

Este estudo trará novos fundamentos à teoria da Filosofia na Técnica de Martha Graham sob o enfoque da flexibilidade, caracterizando-se como uma pesquisa de campo e bibliografia de abordagem qualitativa, no sentido de observar, considerar, reconhecer e contribuir para a dança através da inter-relação com a área de estudo da flexibilidade.

Acreditamos que a pesquisa não apenas fornecerá subsídios para novas práxis pedagógicas aos mestres, coreógrafos e bailarinos na elaboração de aulas e criação de novas coreografias e rumos para a dança, como também produzirá conhecimentos que inovarão as práticas em escolas de dança, companhias, academias e universidades, além do valor sociocultural que esta pesquisa representa para arte.

Além do que o presente estudo contribuirá significativamente ao cotidiano da prática pedagógica, promovendo maior embasamento metodológico entre os profissionais da dança, além de ajudar no crescimento pessoal de cada um, melhorando, com a troca de conhecimento, a interrelação entre os bailarinos provocando e analisando o trabalho da performance em geral, por meio da junção da técnica de dança moderna $X$ flexibilidade.

Ao concluirmos estas reflexões sobre a técnica de Níveis de Flexibilidade, e força muscular abdominal em bailarinas submetidas à técnica de dança moderna de Martha Graham, percebemos também, que é fundamental pensar em técnica não de um modo mecânico e sim de sensibilidade, refletindo na autoimagem e consciência do corpo afetivo e social. Este faz parte de uma sociedade que constrói mudanças na cultura dos praticantes de dança moderna, somando ao conjunto de relações emocionais na caminhada de cada um.

Constatamos que é importante destacar que o corpo não é mercadoria e sim algo significativo cheio de intenções visando a formação do homem criativo participativo e transformador.

\section{REFERÊNCIAS}

$A U, S$. Balé e modern dance. London: THAMES AND HUDSON LYDA, 1988.

ACHAR, D. Balé: uma arte. Rio de Janeiro: Ediouro, 1998.

ACHOUR Jr., A. Bases para exercícios de alongamentos relacionados com a saúde e no desempenho atlético. $2^{a}$ ed. São Paulo: EditoraPhorte, 1998. 
ALRICSSON, M., HARMS-RINGDAHL, K., ERIKSSON, $K ., W E R N E R, S$. The effect of dance training on joint mobility, muscle flexibility, speed and agility in young cross-country skiers--a prospective controlled intervention study. Scand J MedSciSports. Aug;13(4), 2003, p. 237-243.

AQUINO, T. Suma Teológica. Primeira parte. São Paulo: Martins Fonte, 2007.

BARIL, J. La dansemoderne d' IsadoraDucan. Paris: VIGOT EDITIONS, 1977.

CAMINADA, E. História da dança: evolução cultural. Rio de Janeiro: Sprint, 1999.

DOBBELS, D. Martha Graham. Paris: EDITIONS BERNARD COUTAZ, 1990.

GARAUDY, R. Dançar a Vida. Rio de Janeiro: Nova Fronteira, 1973.

GARDNER, H. Mentesque criam. Porto Alegre (RS): ARTES MÉDICAS, 1996.

GRAHAM, Martha. Memória do sangue: uma autobiografia; tradução Claudia Martinelli Gama. São Paulo: Siciliano, 1993.

HOROSKO, M. M. G. The evolution of her dance: Theory and training. EstadosUnidos. A capella books, 1991.

HUI, E., CHUI, B. and Woo, J. Effects of Dance on Physical and Psychological Well-being in Older Persons. Arch GerontolGeriatr, 49, 2009, p. 45-50.

JUNG, C. G. Os arquétipos e o inconsciente coletivo. Petrópolis: Vozes, 2002.

$L E A L, M$. A preparação física na dança. Rio de Janeiro: Sprint. 130, 1998.

MOREIRA, W. W. (Org.). Educação Física e Esportes: perspectivas para o século XXI. Campinas: Papirus, 1999.

OKUNEYE, R.O., ADEOGUN, J.O., IDOWU, I. The effects of a six-week aerobic dance programme on selected fitness components and waist-hipratio in adult males. Sierra Leone J Biomed Res, 2(1), 2010, p. 17-22.

SILVA, A.H., BONORINO, K.C. IMC e flexibilidade de bailarinas de dança contemporânea e ballet clássico. Fit Perf J, 7(1), 2008, p. 48-51.
STEINBERG, N., HERSHKOVITZ, I., PELEG, S., DAR, G., MASHARAWI, Y., HEIM, M., SIEV-NER, I. Range of joint movement in female dancers and nondancers aged 8 to 16 years: anatomical and clinical implications. Am J Sports Med. May:34(5), 2006, p. 814-823.

\section{SOBRE A AUTORA}

Possui graduação em Educação Física pela Universidade do Estado do Pará (1985). Mestrado em Educação Física pela Universidade Iguaçu (2004). Doutorado em Ciências do Desporto pela Universidade de Trás-os-Montes e Alto Douro (2013). Atualmente é professora assistente IV da Universidade do Estado do Pará, docente da UNINASSAU, e coordenadora do Laboratório de dança da UEPA. E-mail: sasa_monteiro@hotmail.com 